\title{
Nepali Domestic Workers in New Delhi: Strategies and Agency
}

\author{
Chudamani Basnet \\ Sandhya A. S.
}

\begin{abstract}
Scholars have noted deplorable conditions of female migrant workers who suffer several types of citizenship disabilities as most countries do not extend equal citizenship rights and protections to migrant workers. In addition to this, they are unable to take full advantage of the rights available to them in the host countries because of low cultural and social capital. Further, studies have emphasized how the breakdown of the traditional economy and the penetration of the market in developing societies have forced people, especially from rural areas, to seek low-paying dead-end jobs in the global labor market. Examining Nepali domestic workers in New Delhi, while this research agrees with the existing studies, we also bring to notice the fact that migrant female workers are not always passive victims and that they exercise considerable choice and agency. The case of Nepali domestic workers in New Delhi offers fresh insight into the ways in which migrant women attempt to actively influence and control the work conditions and immediate labour market outcomes. This paper also shows that even if Nepali migrant workers gain in a limited way, they actively collude with their employers to marginalize native domestic workers. In the end, traditional power relations and inequality are reproduced unchallenged.

Keywords: migrant workers, native domestic workers, low cultural and social capital
\end{abstract}

\section{Introduction}

Scholars have noted lamentable conditions of female migrant workers (Abu-Habib,1998; Adib \& Guerrier, 2003; Bauder, 2005; Bauder, 2008; Frantz, 2008; Sassen, 2000). Migrant workers suffer several types of citizenship disabilities as most countries do not extend equal citizenship rights and protections to them (Walia, 2010). Relatedly, because of low cultural and social capital, they are unable to take full advantage of whatever rights are available to them in the host country (Bustamante, 2002). Women are further exploited as cheap and docile labor (Elson \& Pearson, 1981; Mills, 2003). In addition, studies have emphasized how breakdown of the traditional economy and the penetration of market in the developing societies have forced people, especially from rural areas, to seek low-paying dead-end jobs in the global labor market (Castles, 2013). Examining Nepali domestic workers in New Delhi, we mostly agree with the existing studies but, based on our study of micro-dynamics between employers and employees, we also bring to notice the fact that migrant female workers are not always passive victims and that they exercise considerable choice and agency.
We do not, however, mean that they exercise some freewheeling agency. Macro forces as well as their biographical capital, rooted in their past experiences, the particular stage of their life cycles and entrenched "habitus," affect their choices, agency and strategies (Bourdieu, 1990; Bourdieu, 2002 [1986]). As social scientists have long argued, neo-classical economic theories, which depict labour market as atomistic and perfectly competitive, do not capture the nuances of the actually existing labour market. They instead argue that the labour market is profoundly gendered, ethnicized, castecized, and racialized (Adib \& Guerrier, 2003; HarrissWhite, 2005; Mills, 2003; Ridgeway, 1997; Ridgeway, 2009; Ridgeway et al. 2009; Thorat \& Neuman, 2012). At the broader theoretical level, therefore, this study aims to understand the cultural underpinnings of labour market and its consequences for different actors and institutions. The micro-dynamics also help us understand the durability and reproduction of different forms of inequality, since the agents draw on and contribute to the structural and cultural forces that they are enmeshed in.

As has been observed in the West, the Middle East and the rising East Asian economies, India has witnessed the rise of the phenomenon of household domestic workers This work is licensed under the Creative Commons (C) Chudamani Basnet \& Sandhya A.S.

Chudamani Basnet: Assistant Professor, South Asian University, New Delhi, India

Email: cbasnet@gmail.com/https://orcid.org/0000-0001-9593-6562.

Sandhya A. S: Doctoral Researcher at Max Planck Institute for the Study of Societies, Cologne, Germany

Email: sas@mpifg.de/https://orcid.org/0000-0002-3691-386X 
in recent decades. Indian employers in our study seek domestic service of different kinds due to real and perceived "lack of time" because of their regular employment, school or college going kids, and family members needing special care (Basnet \& A.S., 2020, forthcoming). India has also a long history of keeping domestic servants as a "feudal" status symbol (Qayum \& Ray, 2003; Ray \& Qayum, 2009). The preferences in these houses are for part time domestic workers. The domestic workers are asked to wash dishes, clean and mop floor, wash cloth manually or in the machine and clean house in general. Similarly, Nepali migrant women, who came to New Delhi with their husbands as "trailing" wives, work as domestic workers since domestic work, in most cases, does not require legal documents ${ }^{1}$. A lack of "skills" on the part of the domestic servants is not a hindrance as women's work has been historically devalued as "non-work" (Elias \& Louth, 2016).

Focussing on the perspectives and actions of Nepali domestic workers, we show that these migrant women deliberately choose the informal domestic sector. Once they have chosen their area of employment, just like their employers construct an image of the "ideal maid" (Huang $\&$ Yeoh, 2016), Nepali workers too construct an image of the ideal employer and household. Second, once employed, they use a variety of strategies to retain their job and secure additional benefits from their employer. They, for example, actively feign ignorance and passivity to come across as an ideal worker. Such feigned passivity on the part of women workers has also been observed in different times and places (Elson \& Pearson, 1981 for instance). Third, they have to compete with the native workers and accordingly, they engage in specific forms of cultural work that cast their competitors on the negative light. Unlike in the West, where the domestic worker market is formalized to a great extent, the recruitment in India is overwhelmingly informal and done through personal contacts. Cultural work thus becomes even more important in the Indian context ${ }^{2}$.

As poor and barely literate immigrants working as wage earners for the first time in their lives, the Nepali domestic workers contribute to their meagre family income, which enhances their prestige in their patriarchal households (Basnet \& A. S., 2020, forthcoming). Although exploited and heavily constrained in their moves, they nevertheless turn the situation into their favour. The agency that the Nepali domestic workers exercise is one that is geared toward survival in the market economy. Most importantly, the "success" of the Nepali workers

1. Nepalis and Indians have migrated into each other's territories for centuries. For the history of Nepali migration in India, see Bhattrai, 2007; Nath, 2006; and Subba et al., 2009. The Indo-Nepal international border is open and citizens of these countries can cross the border without a visa. Nepalis are seen and found working as restaurant workers, street vendors, construction workers, and security guards in New Delhi and other major cities. By "trailing" wives we mean those women who migrate as wives rather than workers (Yeoh, Huang and Gonzalez III, 1999).

2. We do not, however, mean that intermediary recruitment agencies or state officials apply some rational criteria to judge domestic workers. These agencies are equally likely to use cultural filters to judge and evaluate domestic workers (Bakan \& Stasiulis, 1995). adversely affects the local Indian domestic workers. Consciously or unconsciously, Nepali workers contribute to the marginalisation of the native Dalit and Muslim domestic workers, who have long suffered in their own right. In the end, the strategies of survival in the labour market adopted by the Nepali domestic workers end up reproducing unequal power relations.

\section{Research Site and the Major Actors}

This research was conducted in 2015-2016 at R.K. Puram Sector 1 and 4, one of the central zones of South Delhi. Government offices and residential quarters dot the locality. The employers reside in these quarters and largely belonged to grade II and III (Lower division clerks and stenographers) of central government service class. While most of these quarters are allotted to the male members of the house, a handful of them are allotted to women too. However, women, not men, deal with the domestic service. These employers come from New Delhi as well as from other Indian states. They are middle and upper caste Hindus, bilingual and call themselves middle-class.

Several slums in the area sit uncomfortably in the otherwise sanitized government quarters. The "camps" and "jhuggis" of the locality cater to the domestic help market. Jhuggis, loosely translated as slums, are not a visual and olfactory pleasure for employers and local residents. They also generate a sense of fear among the residents, noticeably performed in the demarcation of space through barbed wires around jhuggis and the quarters. In the research site, there are primarily two such jhuggis: a Muslim jhuggi and a Nepali jhuggi, also known as the parvatia camp ${ }^{3}$. While there are a handful of Nepalis in the Muslim jhuggi, there are some Muslims and Christians who are not necessarily Nepali in the Nepali jhuggi. The Muslim jhuggi, not very far from the Nepali camp, is occupied primarily by Muslim families from Kolkata who speak Bengali. On the other hand, the Nepali jhuggi primarily constitutes first-generation Nepali migrants largely from places such as Rolpa and Gulmi in Nepal's central hills. Both these slums have many "low caste" Hindu migrants from the Indian states of Uttar Pradesh (UP) and Bihar, occupying their jhuggis and competing with them in the local labour market.

Historically, low caste women have served wealthy high-caste households in various capacities in India. In recent years, many low-caste men and women as well as Muslims, have worked for the public sector as "jamadaars" or cleaning staff (Harriss-White, 2005; Ravichandran, 2011; Tripathi, 2012). Some of them work for the local Post Office informally and through small contracts. The Indian employers identify the domestic workers from this group as "Bhangis," a historically oppressed low caste (Kumar, 2014; Ravichandran, 2011; Tripathi, 2012)4.

3. parvatia means those from the hills. All the Nepali migrants we spoke to come from the hilly regions of Nepal.

4. Bhangis is a popular name, at times used pejoratively, for the scavengers in north India, and they bear different names in other parts of India. Various Indian governments since Independence has tried to 
The major actors in the local domestic worker's market, therefore, includes Bengali speaking Muslim domestic workers, Hindi speaking Hindu women from U.P and Bihar, Nepali immigrant women and their Indian Hindu employers. Unless otherwise stated, all the domestic workers we discuss in this paper work part time in multiple households.

We conducted qualitative interviews and observations in 15 households, largely speaking to the female employers and their domestic workers, as men rarely dealt with issues pertaining to domestic servants. All the personal names appearing in the paper are pseudonyms. The fact that the co-author was born and brought up in the area helped locate these households. The interviews were conducted in Nepali and Hindi. These households have had experiences with Nepali and Muslim and low caste Bhangi domestic workers. All the employers we interviewed had been living in the locality for the past two to three decades. The interviews with employers were conducted at the employers' households and the workers were interviewed at employer's households as well as at their residences. The interviews focussed on the recruitment process, work experience and daily interactions between the employers and the employees. The interviews were transcribed and analysed for key themes.

\section{Becoming a Worker: From Housewives to Domestic Workers}

Little is known about the history of Nepali women's migration to Indian towns and cities ${ }^{5}$. Our interviews with senior residents at the parvatiya camp indicate that Nepali women started migrating to India in the 1970s. In recent years, they have started migrating to the Middle East as workers, but all the women interviewed in this study were "trailing" spouses, i.e., they came to India with their husbands after their marriage as inheritors of patriarchal marital ties (Yeoh \& Huang, 1998; Yeoh, Huang \& Gonzalez III, 1999). It is only after they "established" themselves here that they started working to supplement their family incomes. Social and familial networks are integral to migration and scholars have long noted the significance of these ties in the mobility of people, recruitment and adaptation in the host country (Gurak \& Caces, 1992; Thieme, 2006).

The recruitment of household workers by Indian employers takes place through informal networks. Indian employers rely on traditional stereotypes, anecdotal reform the scavenging profession, particularly cleaning human excreta manually. Bhangis are disproportionately represented in the occupation. The reforms, however, appear to have largely failed (Kumar, 2014; Ravichandran, 2011; Tripathi, 2012).

5. As noted above, Nepalis and Indians have migrated into each other's territories for centuries. There is a sizable population of Nepali language speaking Indian citizens who are often confused with immigrant Nepali workers upon which this study focuses (Subba et al., 2009). In recent decades, as the Nepali economy has stagnated and Nepal has faced a series of political crisis, it is believed that the number of migrants has dramatically increased in recent decades (Bhattrai, 2007; Seddon, Adhikari \& Gurung, 2002). Estimates of the Nepali migrant workers in India vary from half to 3 million (Graner \& Gurung, 2003). experiences, religion, and caste to construct an image of the ideal domestic worker. Nepali workers on their part strategize in their own ways. Most of the migration from Nepal to India is organized around social networks of migrants. Most families in the camp also were distantly related to each other (by blood or by their affinity to the same village). These networks, once settled, also play an important role in recruitment as one Nepali worker recommends another's name if she is not free to take up a new assignment.

Nepali domestic workers choose the job while others have switched to become domestic workers after having realised the "problems" with other jobs. As Maya, a 50 years old woman from Central Nepal, says,

I would easily get jobs in shops...They pay well too. But this [the work as a domestic worker] is better. We have the habit of bending and doing chores, so it's not a problem for us. My daughter cannot do this. Also, it's easy to do. In shops, you don't get time to relax! Somebody is always on top of you, dictating what to do. Here there is freedom. I can do work in 3-4 houses and go back to my home and rest. Many people also give breakfast and lunch... sometimes even clothes and other things. And we can always ask for leave and go to the gaun [the village in Nepal]. That is not possible in these shops because they want workers all days in the week...

Maya's narrative points out that she is quite aware of the several opportunities in the low paying Indian informal job market. She chose to work as a domestic worker even if she had other options like working in the retail shops, something that her daughter does. We also see that several biographical and structural factors have led her to the job of a domestic worker, nevertheless, her choice is evident. We also see that her "habitus" is important (Bourdieu, 1990). As someone who grew up in a poor patriarchal household with the gendered division of labour, the job of domestic worker comes rather "naturally" to her (Elson \& Pearson, 1981; West \& Zimmerman, 1987).

Her life cycle also affects her biographical capital. She cannot continuously work for long hours as she used to do when she was young. Besides, she does not want to be supervised round the clock. Only the type of part-time jobs like the domestic work gives her "rest" and "freedom." Also, by working as a domestic worker, in contrast to other similar jobs, she secures "extra" benefits like food and clothes. Finally, these women maintain close contact with their kin back in the Nepali Hills and they frequently return during festivals and other emergencies. These part-time jobs give them the freedom to leave their job whenever they want to go back to their villages in Nepal and rejoin it later when they have come back. Maya's narrative shows how, on the one hand, she is constrained by her habitus and cultural capital, but, on the other hand, exercises agency and choice at the same time. It is wrong to understand her actions as mere helplessness and inconsequential on the part of an immigrant worker (Bauder, 2005; Madden, 1981).

Once they have decided to enter the domestic service jobs, the Nepali domestic workers are aware of the fact 
that all employers are not the same. Just as the employers have an image of the "ideal maid" (Huang \& Yeoh, 2016), they too construct an image of the ideal employer and household. For instance, Lakshmi, a 40-year-old lady from Nepal's central region, says that she does not prefer working in South Indian houses because:

Arrre they are very different! They keep shouting in weird language angadapungada (imitates, laughs). And you don't understand what they are saying. Whether they are praising you or criticising you, its all the same (laughs). How would you know whether they are not talking nasty things about you?... And we can know if they are gossiping about us (laughs). South Indians are just...we don't understand them.

Lakshmi here classifies her employers in terms of relative distance from her own cultural standard. These Nepali workers have a working knowledge of Hindi, but they do not know other Indian languages or English. It is not simply that Nepalis hold stereotypical images about South Indians on the basis of language; but there is a subtle logic and calculation in their preference. In this job, domestic workers are continuously judged, about which they must be vigilant since the employer's judgement determines their wage and non-wage rewards. The women also want to make sense of their moral worth through the way the employers talk about them. So it is important for them to understand the languages of the employer, explaining why Lakshmi prefers to work in a household which speaks in Hindi and wishes to avoid South Indian employers.

In addition, the Nepali domestic workers also take note of family size and the drudgery involved when making a decision about a particular employer. The number of people and children in the house is an important criterion, as Maya says:

I was once requested to work for a house where only bachelors stayed. This house was the one near the market. I refused. How could you trust bachelors? Even married men cannot be trusted.

Shanti thus does not trust the single men even if they come from "right" social backgrounds and geography. In India, sexual violence against women makes frequents headlines. While her characterization that all men are bad may limit her options, her assertion comes from her own gendered experience of sexual violence in South Asian patriarchal society and households. In one instance, for example, she quit her job after a married man, the husband of her female employer, made unwanted sexual advances toward her ${ }^{6}$. Note also here that as an immigrant poor woman lacking necessary social and cultural capitals, these domestic workers do not think of going to the police or government agencies for help (Raj \& Silverman, 2002).

To summarize, looking at the job of domestic worker from "top" might lead one to believe that these workers are "placed" into specific occupations and are forced into performing the task without having any choice in the matter. Our study clearly shows otherwise. Nepali domestic workers choose the domestic work and take key

6. According to one respondent, whenever married men, husbands of their madams, have made sexual advances, they often threaten the men of complaining to the madam (the wife). But often the wives take the side of their husbands. decisions pertaining to the nature of the household based on their image of an ideal household or employer. They reported that they sometimes get caught off guard when their ideal employer does not meet their expectations. In such situations when they feel "uncomfortable" with their employer, they simply quit and hunt for an alternative.

\section{On the Job: Strategic Submissiveness and Obedience}

Once the domestic workers have located an ideal employer, they use a variety of means to "impress" their employers not just to retain their job but also to secure extra benefit that these workers accrue if they behaved "properly." We noted above that the labor market is gendered, sexualized, racialized, and ethnicized in numerous ways and stereotypes come in handy in the process. Accordingly, Nepali workers in North America and elsewhere are seen as obedient, docile, gentle and polite, thus easily controllable for the employers (Graner \& Gurung, 2003; Gurung Hamal, 2009; Hamal Gurung \& Purkayastha, 2013). In New Delhi too, Indian employers hold similar images of the Nepali domestic workers. The Indian employers frequently said that the Nepali women were "very sweet" and that they "keep smiling." Nepalis have long been stereotyped as poor but happy people. Our interviews with the employers confirm these stereotypical images, but we also observed that Nepali domestic workers subtly use these stereotypes strategically to their advantage.

One of the ways these migrant workers do this is by executing the unspoken rule by which the domestic workers perform a right amount of extra work for which they receive "surprise gifts" in the form of food and old clothes. They would not ask for extras, but would never refuse if they are offered, which then becomes a routine for both the domestic worker and the madam. As Priya, a Nepali domestic worker, says,

...we give them [employers] something free. So if I am supposed to do laundry, wash utensils and mop the floor, once in a while, I do something extra without being told. So I would clean the carpets or clean the sink or water the plants. I am not being paid for this... See who doesn't like free things?...Everyone likes free things... But if I do it without telling Madam that I am doing it she becomes pleased...She then thanks me for that. Would she thank me for the regular work? No, right?

Priya does extra things without being told to do so. This adds "free things" to her meagre salary she receives from her employer. But she wants to do only the right amount of free work. She adds,

....but...I don't do it very often. See what happens is, when you keep doing things like this, it loses its value, and it becomes a routine. She will then start expecting it to be done every day! ...We, therefore, need to know when to give the free things (laughs).

Priya obviously makes subtle and cautious choice to impress her employers. She does not want to normalize her practice of doing extra work so as to raise her employers' expectations. Using "we," i.e., speaking collectively on behalf of the domestic workers, she says that we "need to 
know" when to give them free things. Here, she appears to be actively strategizing and controlling her work conditions and relations. But by accepting extra things for her extra work, she makes a moral claim on the "freebies." She thus denies her employer the claim that the employer was a particularly kind-hearted person. Acts of domestic workers such as these, indeed, make the "madams" happy and domestic workers subtly learn their employers' expectations. As Usha, Priya's employer, confirms:

When Priya cleans the house without being told it suggests that she feels for the house. Won't one clean the carpets of one's own house? It's just like that. She looks at our house as her house...Even if it's not your house technically, you still think of it as yours. Good girls do that...

Usha here validates what Priya said above. She demands that the domestic workers should work as if they are working in their "own houses." These domestic workers know their employers' expectations and formulate their strategies accordingly.

Our interview with the employers shows that the supposed sweetness of the Nepalis is one of the reasons for which they are overtly preferred over their native competitors. But Nepali domestic worker's perspective puts an interesting twist on the employers' narratives. These female workers are cognizant about the employers' construction of their image and strategically take advantage of this construction. As Pooja, a 39-year-old domestic worker from central Nepal, says:

Well, we have to be sweet, right? Who doesn't like smiling faces?...We are poor and uneducated people... they don't expect us to comment strongly on things. Their ego will get hurt if we start answering back. If we are humble, their ego doesn't hurt...And we can't retain our job if they stop being happy with us...sometimes you also have to pretend that you don't understand anything. Yes, they will think that you are stupid, but at least you can save yourself from all that scolding, no?

Here, Pooja is showing her helplessness as well as the tactic of passivity. On the one hand, she admits that she is a helpless "poor and uneducated" person, who must master the language of smile and sweetness in front of her employer. But her smile is also performative and strategic. She wants to inflate the ego of the employer which would ensure her continued service and gifts in the household. She admits having faked and feigned stupidity to impress her employers. The "culture of servitude" is not just imbibed, but it is also tactfully used by these domestic workers to ensure the continuity of their jobs and other benefits.

The Nepali domestic workers, by showing passivity, sweetness, and submissiveness to their Indian female employers, make the best use of the cultural tools of feigning docility, securing their employment and their sense of occupational identity. Clearly, a good deal of these Nepali domestic workers' portrayal of themselves is a strategic action with a tactful use of practical reasoning (Bourdieu, 1990; Durrenberger, 2005; Elson \& Pearson, 1981).

\section{Nepali Migrants and the Native Domestic Workers}

The local households in the concerned locality have had a history of employing Muslim and Bhangi domestic workers, but once the "trailing" wives of Nepali immigrant men arrived in a significant number after the Maoist insurgency (1996-2006) that rattled the Nepali hills, the employers no longer found the native domestic workers desirable and persistently indicated a preference for the Nepalis (Basnet \& A.S, 2020, forthcoming). Highcaste Indians in general and the employers we studied in particular view Muslim and Bhangi domestic workers negatively. While the employers refrain from making direct references to religion and untouchability, the Bhangis and Muslim workers are stereotyped as "dirty, loud and bizarre." (Basnet \& A.S., 2020, forthcoming). It is also interesting that the employers hardly make any distinction between the Muslims and the "low caste" Bhangis in their narratives, perhaps because both the groups have been historically associated with "polluting occupations" such as cleaning as well as the skin and hide trade and thus fall outside the traditional Hindu "varna" system (Dumont, 1999 [1970]).

In contrast, as indicated above, Indian employers construct both positive and negative images about the Nepali domestic workers. In this respect, their representation of the Nepali domestic workers is not very different from those in North America and elsewhere, where Nepali workers are depicted as poor, obedient, and docile (Graner \& Gurung, 2003; Gurung Hamal, 2009; Hamal Gurung \& Purkayastha, 2013). But they are also cast as honest, brave, and at times "moody." The latter "positive" stereotypes probably come from the image of the Nepalis as "brave" Gurkhas (Caplan, 1991). Nepali Hill men serve in the regular British and Indian armies. The stories of their "bravery" are not uncommon in the Indian media and popular stories. Employers often draw on these stereotypes while recruiting Nepali domestic workers.

Nepali workers on their part quickly learn about the stereotypes held by the Indian society, but they also draw on the clues they get from their employers in their everyday interactions. They then strategically align their discourse with that of their employers. The fact that both the employers and the Nepali domestic workers consider themselves as "Hindus" means that they share a similar worldview to a certain extent ${ }^{7}$. They perhaps internalise the beliefs about Muslims and low-caste Bhangis. The stereotypical images of Muslims and Dalits in Nepal are not uncommon although caste system in Nepal is thought of to be "liberal" than in India (Basnet, 2015; Basnet, 2018; Bista, 1991). Thus, the Nepalis style themselves as good "high-caste" Hindus in contrast to the Muslims and Bhangi others ${ }^{8}$. The Nepali domestic workers, in their turn, play up

7. Nepal used to be a Hindu state until 2006 when it was declared a secular state following an anti-monarchical movement in 2005-6.

8. Employers in fact do know that the "real" caste of their Nepali servants. The Nepalis usually invoke well-known family names, such as Thapa, in 
their positive images while casting their competitors in a negative light. They thus buttress their claim that they are the ideal workers.

We noticed that Nepali workers often use these images in everyday conversations with their employers. For example, we observed when Maya did not come to the household to work for few days. She usually does not do this, and even if she goes on leave, she notifies the family. She came back after 3-4 days and Sunita, her employer, started scolding Maya, asking why she did not inform her or substituting somebody in her place. Maya patiently listened to everything and then started crying for a couple of minutes. Then Maya spoke, displaying the wounds in her body:

See...I was in the hospital... She beat me up! You know those Bhangis, right? Cheap people!...This Bhangi woman, Rajjo, started fighting for no reason. Actually what happened was that while filling water from the common tap, she had kept two buckets... When she came back, she saw that one of her buckets was stolen...She got furious. Since my jhuggi is near the water tap she started to scream using cheap abusive words. All that sister and mother swears! I mean we don't like it, no? We belong to a good family. For these cheap people it might not be a big deal, but for us it is...So I went to her and asked her to stop because my children were inside. You know children learn things fast. So I asked her to stop. Instead of stopping she started to accuse me that I have stolen her bucket. I told her to come inside the jhuggi and find the bucket for herself if she doesn't believe me. When I turned the other side, she suddenly started beating me up with a log of wood!...All these Bhangis are like that!

Maya graphically describes how all the untouchable Bhangis are "cheap," foul-mouthed and quarrelsome. On the other hand, she identifies herself with the employers, claiming that "We belong to a good family." She is worried that her children might learn the abusive languages that the Indian domestic workers allegedly use in public places. It is noteworthy that she is here quite aware of the employers' views about the Bhangis and exploited this to her advantage on this occasion. After narrating the story, she proceeded towards her work. Madan, Sunita's husband, who was listening to the conversation, then commented:

Although these Nepali are poor, they are civilised people. Their economic conditions force them to stay in jhuggis. You know who she was referring to by Bhangis? That jamadar type person who picks up rags and garbage. Kamlesh [the garbage collector of the locality] is also a Bhangi. They come from U. P. Bihar; they completely lack culture! They will use all kinds of cheap language and see what they did to Maya. Poor woman...You (pointing towards his wife) can ask Maya to take a day or two off...

Note here how Madan describes Nepalis as a poor but "civilised" people and the poor untouchables from

Nepal's hills. It is possible that many of them hide their caste background. Probably Indian employers take the clue of the high-casteness of their Nepali workers from the latter's fair skin. The black colour is often associated with the low caste "untouchable" in India (Beteille 1996).
UP and Bihar as "lacking culture." Negative stereotypes about Biharis and U. P. residents are frequent in the Indian labour market. These stereotypes depict people from Bihar and U. P. as lazy and unsophisticated without manners and style (Jodhka \& Newman, 2012). Further, he offers Maya a leave of a day or two without her asking for it. We observed that talks like these routinely take place among employer households in the area. The Nepali domestic workers use these cultural resources to their advantage. In other words, they present themselves as more "native" than the Indian domestic workers from U.P. and Bihar.

Nepali domestic workers use every opportunity to distance themselves from the Bhangis and Muslims. Not only do they characterise their Muslim and Bhangi domestic workers negatively, but also they hold extremely negative views about the Muslims and Bhangis in general. Note how Maya above thought that all the Bhangis were "bad." When asked about her village back in Nepal, Maya says:

It [My village] was great. Farms, streams of river and mountains all together. Where do you find such a thing in Delhi? Our village constituted of Thapas, and we enjoyed get-togethers and festivities. You know the unique thing about our village? Unlike Delhi, it did not have Bhangis and Muslims. So we all had similar culture...

Maya here is nostalgic about the natural beauty in her mountain village in Nepal. She brings up the well-known high-caste Thapa family name to support her claim that her village was "cultured." She then interprets the absence of Bhangis and Muslims as adding to the greatness of her village. In fact, she is not correct in that the Nepali Hills do have a large population of the "untouchables," who often live in segregated settlements. Neither are Muslims unknown in Nepal. The language of "culture" that Maya strategically speaks of is the same what as her employers speak and want to hear. Lakshmi, a 40-year-old lady who came to India in 1994, describes the Muslim domestic workers in this way:

...Who would want to employ them if they are irregular, unclean and foul mouthed? People in these houses are not mad. They can recognise who is honest and who is not. We work for our bread, and we respect that bread.

Muslims don't believe in respecting work, no?

Note here how Lakshmi characterises the Muslims irregular, unclean, and foul-mouthed. She further repeat stereotypical images of Muslims that they do not have work ethic. She is unaware of the systemic and institutional discrimination that the Muslims and the "untouchables" face in the Indian society (Thorat \& Neuman, 2012). Neither does she think that her perceived "high-caste" Hindu status has given her a privileged position in the domestic worker's market. Instead, she says that the Muslims do not respect their owners. They further said that they avoid working at Muslim households. They have stereotypical images of the Muslims including their large family size and unsanitary health practices, which is also shared by their employers. 
The shared discourse between the Indian employers and their Nepali domestic workers help the latter to get and retain employment and in the process, further marginalize the native domestic workers. Nepali workers utilise the cultural resources in such a way that their reservoir of symbols matches with the expectations associated with their employers (Bauder, 2001; Bauder, 2005). In the process, they underemphasize their non-native identity and their own caste and ethnicity but overemphasise their "culture," religion, caste, and "good family background." These are the symbols which they know the Indian employers share and approve of.

\section{Conclusion}

This paper examined the choice and agency that female Nepali domestic workers exercise in the Indian domestic service market, in an attempt to problematize the simplistic description of female migrant workers as docile and meek. We argued that the Nepali domestic workers make key decisions with regards to the nature of work, work conditions and also the employer. They deploy strategies to make their employment prospects and work conditions more favourable in the otherwise bleak labour market. Furthermore, they collude with their Indian employers to marginalize native Indian domestic workers in an attempt to increase their relative competitiveness in the market. In the process, they use strategies that were deeply ingrained in their habitus (Bourdieu, 1990); at other times, they consciously use existing cultural frames and discourses. They influence the behaviour of the employers by painting themselves as the "ideal maid" and participating in reproducing stereotypes about the Muslim and "Bhangi" domestic workers and their community.

The fact that the employers were high or middle caste Hindus worked in favour of the Nepali domestic servants. Clearly, the lowly paid Nepali immigrant domestic workers are not necessarily passive and unthinking victims. This study also shows that that the choices the Nepali female workers and their employers made were embedded into the larger Indian society and culture. It is, therefore, not to be mistaken as the "natural" tendency of the Nepali domestic workers and their employers. It should also be noted that the way the Indian domestic service market is structured at this particular point in history may not remain the same in the future. The preference for a particular type of labour is fluid and fluctuate with time and space. In this sense, the preference for the Nepali domestic workers in this locality might also change in the future, and the definition of a "good" domestic worker and employer may not remain the same if different contenders enter the labour market.

Another important implication of this research is that contrary to the several studies in the Global North where citizenship status plays important roles in the well-being of immigrant women workers (Bakan \& Stasiulis, 2003; Bakan \& Stasiulis, 1995; Yeoh \& Huang, 1998), the immigrant status of Nepali domestic workers actually benefit them. While we acknowledge that the special relationship between Nepal and India-i.e., needing no passport and work permit to work-plays some role in the process to some extent, the cultural strategy both the employers and employees bring to bear on the market is the key to the phenomenon. Even then, this study shows that the relationship between citizenship status and exploitation of women workers is not straightforward and depends on the local political and cultural context.

Finally, although the Nepali domestic workers exercise agency, the structural forces and constraints persist. They are paid pittance as the capitalist economy undervalues their work as unproductive labour. They hardly fight for a rightful and just salary. They fail to see the institutional discrimination faced by Indian Muslim and Bhangi workers. So, even if the Nepali domestic workers feel that they are improving their social and economic positions, they hardly resist their employers or their working conditions as workers, women, or as women workers. In the end, traditional power relations and inequality are reproduced more or less unchallenged.

\section{Acknowledgment:}

We thank Venkata Narayan for his helpful comments. Comments and suggestions from the editors and anonymous reviewers of this journal helped improve the manuscript.

\section{Funding:}

Not Applicable.

\section{Ethical approval for the research:}

No institutional approval for the research is required. Not applicable.

\section{Conflict of Interest:}

We declare that there is no conflict of interest among the co-authors.

\section{Ethical Conduct of Research:}

We declare that this research has been conducted ethically.

\section{References}

Adib, A., \& Guerrier, Y. (2003). The interlocking of gender with nationality, race, ethnicity and class: the narratives of women in hotel work. Gender, Work \& Organization, 10(4): 413-432.

Bakan, A., \& Stasiulis, D. (2003). Negotiating citizenship: Migrant women in Canada and the global system. Springer.

Bakan, A. B. \& Stasiulis, D. K. (1995). Making the Match: Domestic placement agencies and the racialization of women's household work. Signs 20(2): 303-335.

Basnet, C. (2015). Inter-caste relations and intermarriage among Non-Dalit hill castes in Eastern Nepal. Contribution to Nepalese Studies, 42(1), 167-186.

Basnet, C. (2018). Relition or political institutions? Revisiting Dor Bahadur Bista's Fatalism and Development Thesis. Studies in Nepali History \& Society, 23(1), 33-58. 
Basnet, C., \& A. S., S. (2020, forthcoming). 'This is our culture': Indian employers and their maids in New Delhi. South Asia Research.

Bauder,H. (2001). Culture in the labor market: segmentation theory and perspectives of place. Progress in Human Geography, 25(1), 37-52.

Bauder, H. (2005). Habitus, rules of the labour market and employment strategies of immigrants in Vancouver, Canada. Social \& Cultural Geography, 6(1), 81-97.

Beteille, A. (1996) [1965]. Caste, class and power. Oxford University Press.

Bhattrai, R. (2007). Open borders, closed citizenships: Nepali labour migrants in Delhi. Institute of Social Studies.

Bista, D. B. (1991). Fatalism and Development: Nepal's Struggle for Modernization. Orient Longman.

Bourdieu, P. (1990). The logic of practice. Polity Press.

Bourdieu, P. (2002 [1986]). The Forms of Capital. In N. W. Biggart (Ed.), Readings in Economic Sociology (pp. 280-291). Blackwell.

Bustamante, J. A. (2002). Immigrants' vulnerability as subjects of human rights. International Migration Review, 36(2), 333-354.

Caplan, L. (1991). 'Bravest of the Brave': Representations of 'The Gurkha' in British Military Writings. Modern Asian Studies, 25(3), 571-597.

Castles, S. (2013). The forces driving global migration. Journal of Intercultural Studies, 34(2), 122-140.

Durrenberger, E. P. (2005). Labor. In J. G. Carrier (Ed.), A Handbook of Economic Anthropology (pp. 125-140). Northampton, MA: Edward Elgar Publishing.

Elson, D., \& Pearson, R. (1981). 'Nimble Fingers Make Cheap Workers': An Analysis of Women's Employment in Third World Export Manufacturing. Feminist Review, 7(1), 87-107.

Frantz, E. (2008). Of maids and madams: Sri Lankan domestic workers and their employers in Jordan. Critical Asian Studies, 40(4), 609-638.

Graner, E., \& Gurung, G. (2003). Arab ko lahure: Looking at Nepali labour migrants to Arabian countries. Contributions to Nepalese Studies, 30(2), 295-325.

Gurung Hamal, S. (2009). Nepali female migrants and informalization of domestic care work: service or servitude? Journal of Workplace Rights, 14(3), 375396.

Gurung Hamal, S., \& Purkayastha, B. (2013). Gendered labor: Experiences of Nepali women within pan-ethnic informal labor markets in Boston and New York. In A. R. G. Nilda Flores-Gonzalez, Maura Toro-Morn, Grace Chang (Eds.), Immigrant women workers in the neoliberal age (pp. 81-95). University of Illinois Press.

Harriss-White, B. (2005). India's market society: Three essays in political economy. Three Essays Collective.

Huang, S., \& Yeoh, B. S. (2016). Maids and ma'ams in Singapore: Constructing gender and nationality in the transnationalization of paid domestic work. Geography Research Forum, 18: 21-48.

Jodhka, S. S., \& Newman, K. (2012). In the name of globalisation: Meritocracy, productivity and the hidden language of caste. In S. T. a. K. S. Newman (Ed.), Blocked by caste: Economic discrimination in modern India (pp. 52-87). Oxford University Press.

Kumar, V. (2014). Scavenger Community at the Crossroads: Reflection on State Intervention, Welfare and Abstruse Welferism. Indian Journal of Dalit and Tribal Social Work, 2(1/1), 1-11.

Madden, J. F. (1981). Why women work closer to home. Urban Studies, 18(2), 181-194.

Mills, M. B. (2003). Gender and Inequality in the Global Labour Force. Annual Review of Anthropology, 32(1), 41-62.

Nath, L. (2006). Migration, insecurity and identity: The Nepali dairymen in India's Northeast. Asian Ethnicity, 7(2), 129-148.

Qayum, S., \& Ray, R. (2003). Grappling with modernity: India's respectable classes and the culture of domestic servitude. Ethnography, 4(4), 520-555.

Ravichandran, B. (2011). Scavenging Profession: Between Class and Caste? Economic and Political Weekly 46(13), 21-25.

Ray, R., \& Qayum, S. (2009). Cultures of servitude: Modernity, domesticity, and class in India. Stanford University Press.

Ridgeway, C. L. (1997). Interaction and the conservation of gender inequality: Considering Employment. American Sociological Review 62(2): 218-235.

Ridgeway, C. L. (2009). Framed before we know it. Gender \& Society, 23(2), 145-160.

Ridgeway, C. L., Backor, K., Li, Y. E., Tinkler, J. E., \& Erickson, K. G. (2009). How easily does a social difference become a status distinction? Gender matters. American Sociological Review, 74(1), 44-62.

Sassen, S. (2000). Women's burden: Counter-geographies of globalization and the feminization of survival. Journal of International Affairs, 53(2), 503-524.

Seddon, D., Adhikari, J., \& Gurung, G. (2002). Foreign labor migration and the remittance economy of Nepal. Critical Asian Studies, 34(1), 19-40.

Subba, T. B., Sinha, A., Nepal, G., \& Nepal, D. (2009). Indian Nepalis: Issues and perspectives. Concept Publishing Company.

Thorat, S., \& Neuman, K. S. (2012). Blocked by caste: economic discrimination in modern India. Oxford University Press.

Tripathi, T. (2012). Safai Karmi scheme of Uttar Pradesh: Caste dominance continues. Economic and Political Weekly, 47(37), 26-29.

Walia, Harsha. (2010). Transient servitude: Migrant labour in Canada and the apartheid of citizenship. Race \& Class, 52(1), 71-84.

West, C., \& Zimmerman, D. H. (1987). Doing gender. Gender and Society, 1(2), 125-151.

Yeoh, B. S., \& Huang, S. (1998). Negotiating public space: Strategies and styles of migrant female domestic workers in Singapore. Urban Studies, 35(3), 583-602.

Yeoh, B. S., Huang, S., \& Gonzalez III, J. (1999). Migrant female domestic workers: debating the economic, social and political impacts in Singapore. International 
Migration Review, 33(1), 114-136.

Chudamani Basnet teaches sociology in the Department of Sociology, South Asian University, New Delhi, India. His areas of interest includes politics, economy and religion.

Email: cbasnet@gmail.com

Sandhya A. S. is Doctoral Researcher at Max Planck Institute for the Study of Societies, Cologne, Germany. She is interested in the sociology of migration and labor market.

Email: sas@mpifg.de 